\title{
Democratic Deliberation and the Ethical Review of Human Subjects Research
}

Govind Persad*

\section{Introduction}

The Presidential Commission for the Study of Bioethical Issues (PCSBI) recently introduced and reaffirmed "[ $\mathrm{t}]$ he principle of democratic deliberation" $(2010 ; 2012)$ while noting that it is "a less familiar principle in bioethics than the principles of beneficence and justice" $(2010,30)$. No other prominent set of bioethical principles lists a similar principle (Veatch 2007). Though new to bioethics, democratic deliberation has been employed elsewhere in practical ethics (Gutmann \& Thompson 2004, 1819, 31, 33).

This chapter explains democratic deliberation and considers its implications for ethical review of human subjects research. It argues that democratic deliberation favors the inclusion of research participants' perspectives in ethical review, as well as the ethical review of "public benefits" research.

\section{Democratic Deliberation Explained}

Democratic deliberation involves a public exchange of ideas within and across groups of ordinary citizens, experts, and political representatives. Participants should aim to engage actively with one another, and to offer reasons that are acceptable and intelligible to their interlocutors. Decisions should be revisable as new information and new perspectives come into view (PCSBI 2010).

The PCSBI emphasized the deliberative character of its own procedures, in particular when engaging with religious and moral concerns about the synthetic biology innovations it was then evaluating $(2010,139)$. These examples of public involvement far exceed the current requirement in human subjects research that an Institutional Review Board include a nonscientific and a lay member (Fost \& Levine 2007).

Incorporating democratic deliberation into decisionmaking can render the resulting decisions both more respectful and more accurate. First, by involving all parties in the decisionmaking process, democratic deliberation can ensure that the process's outcomes, whatever they are,

\footnotetext{
* Visiting Scholar, Department of Medical Ethics and Health Policy, University of Pennsylvania; J.D. Stanford Law School; Ph.D. Candidate, Philosophy, Stanford University. This is a preprint of a book chapter forthcoming with MIT Press.
} 
express participants' values. Amy Gutmann, the PCSBI's current chair, has argued that even when some lose out in democrative deliberation, the outcome is not imposed on them, but instead results from something they authorized (Gutmann \& Thompson 2004, 21-23). Such authorization can differentiate a just from an unjust outcome, even when the content of the two outcomes is identical.

Other legal and political contexts feature democratic deliberation. For example, recent innovations in restorative justice emphasize deliberative engagement between criminals and victims, which makes it possible for both to see the legal resolution as just (Parkinson \& Roche 2004, 510). Within the civil law, deliberative engagement helps ensure that contentious processes - such as divorce proceedings and family disputesrespect both prevailing and defeated participants (Menkel-Meadow 2004, 361).

Deliberation can enhance accuracy as well as respectfulness. Each participant in deliberation brings a distinctive positional perspective; an ordinary citizen may have less technical knowledge than an expert but more knowledge about how people are employing technology (Anderson 2003, 57). A well-structured deliberative body can, ideally, know more than even its most knowledgeable individuals, rather than simply knowing as much as its average participant (Gutmann \& Thompson 2004, 12).

\section{Participatory Inclusion: Involving Research Participants in Ethical Review}

As we consider how to revise existing human subjects research regulations, consider that a revised Common Rule might incorporate democratic deliberation by drawing on the experience of research participants themselves when reviewing human subjects research proposals. The current regime charges IRBs with protecting research participants, but assigns no member the task of representing research participants. While IRBs must "safeguard[] the rights and welfare of human subjects," they are neither required to engage deliberatively with research participants nor to provide a voice for participants in the ethical review process. The lay member on the IRB is not required to learn about, or advocate for, research participants' concerns.

In contrast, professional ethics and policy review boards outside research ethics frequently represent the clients, governments, and professionals they regulate or protect (Porter 1987). These boards exemplify the participatory inclusion of laypeople (Johnson 2009; Agarwal 2008). Numerous legal provisions ensure the participatory inclusion of clients on committees that regulate clinical research and medical care, as the following 
table indicates.

[Table 1 near here]

\section{A. Participatory inclusion as democratic deliberation}

How do participatory inclusion statutes advance democratic deliberation? Review boards that are not directly democratic (say, the National Park Service's board of directors) often are thought of as democratic because a democratically elected official (the President) appoints an officer (the Secretary of the Interior) who in turn appoints the board. In contrast, participatory inclusion aims at more direct legitimacy, by mandating that the board reflect the perspectives of a variety of interests.

Does having a representative group member on an advisory board suffice to drive that group toward democratic deliberation? I'll consider three potential objections: (1) that representing research participants on boards doesn't help protect them and can even hurt their interests; (2) that research participants' interests are best served by a notice-and-comment or survey process rather than a representative member on a board; and (3) democratic deliberation should have no special solicitude for research participants.

\section{Does participatory inclusion protect participants?}

Rand Rosenblatt worries that a participant representative on an advisory board might provide a veneer of approval without substantively influencing the board's decisions (Rosenblatt 1978). Concerns that procedural protections such as rights of voice and representation are inferior to substantive protections have arisen elsewhere in criminal and civil law (Cassell 2011; MacCoun 2005), and in the development of community advisory boards for clinical research (Recommendations 2009). This concern would counsel against representing participants on boards and in favor of instead writing strong participant protections into research regulations. Such a suggestion would parallel the more general argument that an advisory committee can deliberate effectively regardless of its composition, and that considering a committee's output is enough to assess its deliberation (Walters 2012, 681). But for deliberation to be effective, participants in deliberation must "represent a personal, educational, and cultural variety of life experiences" (Estlund 1997, 191) — a requirement that advisory committees without any review of membership are not guaranteed to satisfy. 
Despite his initial worries, Rosenblatt concludes that involving participants in a process can both produce empowering outcomes and itself be empowering:

[I]t is important to remember that the value of consumer participation and agency explanation does not lie solely in the opportunity to secure a different outcome. What Professor Tribe has termed "the right to be heard from, and the right to be told why ... express the elementary idea that to be a person, rather than a thing, is at least to be consulted about what is done with one." Expressed in political terms, this root concept of human dignity highlights the need for a reconstruction of the democratic process, in which consultation over fundamental human needs is not made meaningless by a labyrinthine bureaucracy. By offering unorganized interests the right to participate in programs for their own benefit, the traditions of structural due process also help to encourage its exercise and thereby help to strengthen democratic capacity (264, 1978).

In the Medicaid context, Rosenblatt therefore endorses "medical care advisory committees," which "include Medicaid recipients and other consumers (as well as providers) in the policymaking process" by giving them "adequate opportunity for meaningful participation in policy development and program administration" $(264,1978)$.

\section{Survey representation versus personal representation}

A different way of including, rather than just protecting, participants would be a notice-and-comment process analogous to the requirement that administrative agencies solicit and respond to public comments when they engage in rulemaking (Cuellar 2005, 421). For instance, ethics review committees might be required to survey research participants and consider the results when deciding whether to renew or approve protocols.

The choice between participatory inclusion and surveys raises some of the same issues that arise in choices between representative and direct democratic approaches, with the caveat that the representative here is not elected, but rather selected by discretionary choice from a group. As such, a better analogy than the choice between representative democracy and direct democracy might be the choice between direct democracy (participatory inclusion) and a citizens' jury (surveys). Citizens' juries attempt to achieve what Hanna Pitkin calls descriptive representation, which ensures that the representative is relevantly similar to her constituency $(80,1967)$. 
Survey approaches may lack sufficient voice in a representative system. To see why, imagine that, instead of adding new Senators when admitting a new state, new states were instead represented in the Senate through surveys: whenever a bill is proposed in the Senate, new states would be surveyed and the existing Senators would be required to attend to the survey results. The new states might complain that (1) Senators will not be held accountable for attending to the survey results, and (2) minor decisionmaking will either require a surfeit of referenda or exclude those represented by surveys. Similarly, a survey of research participants might not be taken seriously by a review board and would be unable to anticipate specific issues that arise in ethical review. In contrast, a participant representative would be on equal footing with other board members and well-placed to investigate and deliberate about major and minor issues as they arise. Finally, participatory inclusion approaches do not rule out the use of surveys: the representative, for instance, could survey other participants as part of her review process.

3. Why represent research participants at all?

What is the normative argument for setting aside special seats for participants? After all, IRB-reviewed research is supported by tax revenue, and benefits many individuals in society who do not participate in research, yet there is no movement to represent these beneficiaries on IRBs.

The prevalence of participatory inclusion requirements on boards analogous to ethics review bodies offers some reason to think setting aside seats for participants is justified. But a more theoretically developed account can be found in discussions of consociational democracy. Andreas Føllesdal describes a consociational system as follows:

[C]onsociational democracy . . . is a non-territorial form of federalism, characterized by cooperation among elites of different segments of a society, often split along religious or ethnic lines. It entails government by grand coalitions, granting autonomy to groups with veto rights over matters important to them $(202,1998)$.

Like consociationalism, participant representation constitutes "nonterritorial federalism": research participants should be represented in decisions that affect them, even if we do not grant them "veto rights" as the consocialist might (Cuellar 2005, 417). Joshua Cohen and Joel Rogers have similarly suggested that we open up more arenas in democracies for decisionmaking by bodies of representatives of particular interest groups 
(1992).

\section{B. Participatory Inclusion in the Human Subjects Research Context}

Many participatory inclusion provisions include clients. Others include people whom institutions evaluate or regulate. Participants are both objects of evaluation and clients: as such, participatory inclusion seems no less appropriate in a research context than in either of the two it melds.

How might research participants' perspectives be better integrated into the ethics review process via participatory inclusion? Laurie Flynn and Ronald Honberg suggest that IRBs reviewing mental health research should "require the inclusion of individuals who have personally experienced severe mental illnesses as consumers or family members," because "consumers and family members, by virtue of their personal experiences, are more likely to focus on those aspects of research designs which may impact (positively or negatively) on the well-being of vulnerable research subjects" $(188,1998)$. Flynn and Honberg, however, mandate the inclusion of patients, rather than research subjects. The two are different

Additional regulations on IRB composition along the lines Flynn and Honberg suggest, however, may exacerbate concerns that IRBs are overbureaucratized (Fost \& Levine 2007, 2196). Regulations on composition that prevent IRBs from achieving a quorum could produce "substitution effects," such as pressures to strip jurisdiction from IRBs, that undermine their direct effects.

Concerns about overbureaucratization might counsel permitting and encouraging, but not requiring, that research participants be represented in ethical review. This parallels the approach ultimately taken in staffing the boards of the PPACA's health insurance "exchanges." Public comment suggested that board members should have various specific forms of expertise and background. HHS responded by requiring that "at least one member of the Exchange's board must include one voting member who is a consumer representative," but stopped short of mandating more specific expertise.

Representation by advocates rather than fellow participants is also possible, and might help alleviate overbureaucratization concerns by widening the pool of potential representatives or allowing current nonscientific IRB members to serve as advocates. Some nonscientific or unaffiliated members required by current IRB regulations see their roles as including "[r]epresenting . . . human subjects' interests"; "[r]eviewing the research from the point of view of a potential subject"; "[a]cting as the ally or the peer of the research subject," and "[a]cting as a patient advocate and surrogate subject" (Porter 1997, 2 tbl. 1). Nonvoting observers or advisors 
who explicitly represent research participants' perspectives might augment the phenomenon Porter identifies: Sirotin et al. suggest that "[p]rofessionals who work extensively with prospective research populations could help articulate those perspectives and should be encouraged to formally explore those perspectives, perhaps through focus groups and interviews," and that "IRBs might also work with research subject advocates, who work closely with research participants and seek to represent their perspectives" (2010, 15). Advocates may have expertise that makes them better able to protect participants' interests, may not be vulnerable to conflicts of interest, or may have broader expertise in the conduct of research than individual participants might. These arguments might be counterbalanced, however, by the advantages of descriptive representation (Minow 1991, 278-79).

Those revising research ethics regulations should consider more explicitly including research participants' perspectives in review. 45 C.F.R. $\$ 46.107(\mathrm{f})$, which provides that the IRB may "invite individuals with competence in special areas to assist in the review of issues which require expertise beyond or in addition to that available on the IRB," may already allow the inclusion of participants. The current wording frames the invitees as technical experts, which might seem to exclude participants. But this provision might be understood, or even reworded, to recognize the experiential expertise of research participants - a form of special knowledge that they acquire through experiencing a medical condition and participating in the research enterprise from the participant perspective (Bal, Bijker, and Hendriks 2004, 1340), just as it has been understood to include expert bioethicists (DeRenzo \& Wichman 1990, 6). While the current provisions make the expert members nonvoting members, the rules could be revised to grant research participant members a voice as voters.

Meanwhile, although 45 C.F.R. $\$ 46.111$ (b) directs the IRB to specially scrutinize the substance of research on vulnerable subjects, it could also justify modifying the review procedure, and thus present an avenue for participant inclusion. Where research proposes to involve vulnerable populations, protecting their interests may counsel democratically including them or their representatives in the deliberations leading up to research approval. The numerous participatory inclusion requirements in statutes regulating mental health, elder care, and disability issues outside of research lend support to such an approach. Indeed, IRBs reviewing research on prisoners already are required to include a "prisoner or prisoner representative under 45 CFR $\$ 46.304$.

\section{The Need for Ethical Review of Public Benefits Research}

Democratic deliberation also has implications for the exemption of 
public benefits research - experimental research on the efficacy of programs like Medicare and Medicaid-from IRB review under 45 C.F.R. $\S 46.101(\mathrm{~b})(5)$. The ANPRM suggests expanding the exemption. But deliberative democratic concerns counsel against such expansions. Public benefit research has the potential to force beneficiaries of public programs like Medicaid — who are often socially and economically vulnerable — into research whose intended aims may be contrary to participants' interests. In contrast, ethical review of public benefits research requires those attempting to revise public benefit programs to get the consent of current beneficiaries, which requires that they explain the proposed changes and provide an account of why research is justified.

\section{A. The Public Benefit Exemption}

The history of the public benefit exemption suggests that it was initially understood as a procedural change, rather than an exemption from ethical review entirely. Amici curiae in two appellate cases, C.K. v. N.J. Dep't of Health \& Human Servs., 92 F.3d 171 (3d Cir. 1996), and Beno v. Shalala, 30 F.3d 1057 (9th Cir. 1994), argued that the public benefits research exemption displaced public benefits research review from IRB oversight, but not from oversight altogether.

Initially, IRBs reviewed public benefits research just as they reviewed other human subjects research, and this practice was upheld in Crane v. Matthews, 417 F. Supp. 532 (N.D. Ga. 1976). Crane prompted the public benefits exemption, which removed public benefits research from IRBs' jurisdiction. However, the Ninth Circuit in Beno recognized that public benefit research exempt from IRB review is still subject to "an examination of the proposed project's potential danger to participants' physical, mental and emotional well-being" (1070). C.K. agreed, stating that "the 'additional layer of review' from which HHS exempted public benefits experiments was the regulatory requirement of IRB review, not the statutory requirement of review for danger" (190).

Some have argued for expanding the exemption beyond research on the benefit levels of federal programs like Medicare and Medicaid, thus exempting a wide swath of research on public benefits. Law professor Elmer Abbo argues that quality-improvement research on dialysis should be exempt from ethical review (Abbo 2007, 579), as does a Hastings Center working group (Lynn 2007, 671). The Secretary's Advisory Committee on Human Research Protections (SACHRP) believes "institutions should be able to apply the exemption to public programs supported by state agencies" as well as to federal programs (SACHRP, 2008).

These arguments have been accompanied by some de facto 
expansion of the exemption. The HHS secretary has exempted randomized trials on the quality of care among Medicare beneficiaries (Peikes 2009).

Research on the allocation rules for transplantable organs (Egan 2006), and on HIV epidemiology in at-risk communities (Merion 2005), has also been exempted. Most strikingly, research on the prevalence of preterm birth and infant death among participants in the Special Supplemental Nutrition Program for Women, Infants, and Children (WIC) was held exempt. This research involved looking through and analyzing infant death certificates, matching the names on the death certificates to the names of children whose mothers received WIC prenatally, and comparing the death rates of AfricanAmerican infants and white infants whose mothers were on WIC (Khanani 2010). One can certainly imagine the mothers — had they been askedrefusing permission to have the death certificates coded in this way and matched, as they were, with factors like race and whether the mother smoked tobacco during pregnancy.

\section{B. Fair Benefits and Public Benefits}

Some have already endorsed the ethical review of public benefits research, though without explicitly invoking concerns about democratic deliberation (Harvard Law Review, 1995; Rosenbaum, 1993, 123-26). Democratic deliberation, I will argue, further favors the ethical review of public benefits research.

Existing advocates have focused the threat that public benefits research poses to participants' medical well-being - that is, the threat that research harms participants. This concern seems to fit into the branch of research ethics that addresses risk-benefit balancing. There is an additional concern, however, that Beno and the federal regulations also seem to recognize: the danger that research will use subjects against their will for the benefit of others. This fits more clearly into the branches of research ethics that address informed consent and respect for participants.

In particular, public benefits research potentially stands in tension with the Belmont Report's dictum that research "should not unduly involve persons from groups unlikely to be among the beneficiaries of subsequent applications of the research" (National Commission 1978, 10). This "fair benefits" requirement is echoed in other statements of clinical research ethics, such as CIOMS's requirement that research be "responsive to the health needs and the priorities of the population or community in which it is to be carried out" (2002). Public benefits research frequently involves taking resources away from poor and disadvantaged beneficiaries to see whether these beneficiaries are able to maintain a tolerable standard of living after losing benefits. As such, the fair benefits requirement may limit 
public benefits research on economically disadvantaged subjects, particularly when conducted for the benefit of more advantaged individuals who want to minimize the tax burden of supporting entitlement programs rather than for the benefit of other disadvantaged individuals.

Jan Blustein demonstrates this ethical tension in discussing the ethics of the National Job Corps Study, a program evaluation that would fall under the current public benefits exception (Blustein 2005, 824). The study randomized some Job Corps applicants into a control group that did not get to participate in Job Corps (a program that offers educational and vocational training to young adults between 16 and 24 years of age). The study was justified on the basis that "random assignment was necessary because it was the only way to provide Congress and the public with credible evidence about the success of the program" (Burghardt, 1997). However, participants complained about being treated as guinea pigs and about the study serving the interests of wealthier individuals, but not their own interests (Blustein 2005, 834). As Blustein suggests:

Research is prima facie unjust if some groups disproportionately bear the burdens and others reap the benefits. Yet over the past 30 years, evaluations have been conducted almost exclusively on public programs that benefit low-income and vulnerable populations. Middle-class benefits like Medicare, the home mortgage deduction, and the college Work-Study programs have been largely untouched. To the extent that participants in social program evaluations assume risk or miss out on desired services, this disparity would seem to raise questions of justice $(2005,838)$.

In a context - that of federal and state entitlement programs - where there is already a "democracy deficit" and where deliberative involvement with current recipients of entitlements is limited, expanding the public benefits research exemption risks allowing research that fails to adequately represent the interests of participants, and so violates the principle of democratic deliberation.

\section{Conclusion}

How would incorporating a democratic deliberation principle change the ethics of human subjects research? I have argued that it would recommend greater inclusion of participants in the review process, and would counsel against exempting public benefits research from ethical review. This would not give deliberation unlimited scope. Legal institutions, for instance, often are initially constructed through intensive 
deliberation, but later governed by systems of rules that grow out of that initial deliberation (Dryzek 2000, 14). Likewise, deliberation might be more important in initial review or the drafting of regulations than in day-to-day enforcement.

Nonetheless, the principle of democratic deliberation supports efforts to make the ethical review of research more publicly accessible. The PCSBI continued to embrace a principle of democratic deliberation in its recent work on human subjects research ethics (2012). The proposals I suggest give this principle content. 
Persad table 1

\begin{tabular}{|l|l|l|}
\hline Participants included & Advisory board & Jurisdiction \\
\hline Benefit recipients & Social Security & Federal \\
\hline Clients (encouraged) & Adult day care & TN \\
\hline Consumers & Health care appeals & $\begin{array}{l}\text { CT; FL; GA; IA; } \\
\text { MA; OH }\end{array}$ \\
\hline Consumers (>50\%) & $\begin{array}{l}\text { Consumer Operated and } \\
\text { Oriented Plans }\end{array}$ & Federal \\
\hline Consumers ( $>50 \%)$ & Health care collaboratives & TX \\
\hline Consumers (2) & Human subjects research & NH \\
\hline Current or former users (>=50\%) & $\begin{array}{l}\text { In-Home Supportive } \\
\text { Services }\end{array}$ & CA \\
\hline Deaf (>50\%) & Schools for the deaf & KY \\
\hline Disabled and advocates (>50\%) & Rehabilitation technology & Federal \\
\hline Hearing aid users & Hearing aid fitters' licensure & RI \\
\hline Mentally ill offenders; relatives & $\begin{array}{l}\text { Mentally Ill Offender Task } \\
\text { Force }\end{array}$ & CO; AZ \\
\hline Professional clients & $\begin{array}{l}\text { Physicians and pharmacists' } \\
\text { licensure }\end{array}$ & SD \\
\hline Recipients; donors; public & Cord blood stem cell banks & IL \\
\hline $\begin{array}{l}\text { Representatives of elderly, needy, or } \\
\text { underprivileged }\end{array}$ & County Boards of Health & GA \\
\hline Sufferers; family & Mental illness advocacy & Federal \\
\hline Sufferers; parents and family & Developmental disability & LA \\
\hline User advocates & $\begin{array}{l}\text { Protection and Advocacy } \\
\text { Service }\end{array}$ & IN \\
\hline Users (>50\%) & Community health centers & AK \\
\hline
\end{tabular}




\section{Reference List}

Abbo, Elmer D. 2007. "Promoting Free Speech in Clinical Quality Improvement Research." Northwestern University Law Review 101: 575-92.

Agarwal, Bina. 2008. "Toward Participatory Inclusion: A Gender Analysis of Community Forestry in South Asia." In The State of Access, eds. Jorrit de Jong \& Gowher Rizvi, 37-70. Washington, DC: Brookings Institution Press.

Anderson, Elizabeth. 2003. "Sen, Ethics, and Democracy." Feminist Economics 9 (2-3): 239-61.

Baily, Mary Ann, et al. 2006. "The Ethics of Using QI Methods to Improve Health Care Quality and Safety," Hastings Center Report 36 (4): S1-S39.

Bal, Roland, Wiebe Bijker, and Ruud Hendriks. 2004. "Democratisation of Scientific Advice.” British Medical Journal 29: 1339-41.

Blustein, Jan. 2005. "Toward a More Public Discussion of the Ethics of Federal Social Program Evaluation." Journal of Policy Analysis and Management 24 (4): 824-46.

Burghardt. J., et al. 1997. Implementing Random Assignment: Lessons from the National Job Corps Study. Princeton: Mathematica Policy Research, Inc.

Cassell, Paul G. 2011. "Freeing the Guilty Without Protecting the Innocent: Some Skeptical Observations on Proposed New "Innocence" Procedures." New York Law School Law Review 56: 1063-96.

Cohen, Joshua, and Joel Rogers. 1992. "Secondary Associations and Democratic Governance." Politics and Society 20 (4): 391-472.

Council for International Organizations of Medical Sciences (CIOMS). 2002. International Ethical Guidelines for Biomedical Research Involving Human Subjects. Geneva.

Cuellar, Mariano-Florentino. 2005. "Rethinking Regulatory Democracy." Administrative Law Review 57 (2): 411-500.

Deeds, Bethany, et al. 2008. "An HIV Prevention Protocol Reviewed at 15 National Sites: How Do Ethics Committees Protect Communities?" Journal of Empirical Research on Human Research Ethics 3 (2): 77-86. 
DeRenzo, Evan, and Alison Wichman. 1990. “A Pilot Project: Bioethics Consultants as Non-Voting Members of IRBs at the National Institutes of Health." IRB 12: 6-8.

Dryzek, John. 2000. Deliberative Democracy and Beyond: Liberals, Critics, Contestations. Oxford: Oxford University Press.

Egan, T.M., et al. 2006. "Development of the New Lung Allocation System in the United States." American Journal of Transplantation 6 (5): 12121227.

Estlund, David. 1997. "Beyond Fairness and Deliberation: The Epistemic Dimension of Democratic Authority." In Deliberative Democracy, eds. James Bohman and William Rehg, 173-204.

Flynn, Laurie, and Ronald Honberg. 1999. "Achieving Proper Balance in Research with Decisionally-Incapacitated Subjects: NAMI's Perspectives on the Working Group's Proposal." Journal of Health Care Law and Policy 1: 174-92.

Follesdal, Andreas. 1998. "Subsidiarity." Journal of Political Philosophy 6 (2): 231-259.

Fost, Norman, and Robert J. Levine. 2007. "The Dysregulation of Human Subjects Research.” JAMA 298 (18): 2196-98.

Gutmann, Amy, and Dennis Thompson. 2004. Why Deliberative Democracy? Princeton: Princeton University Press.

Harvard Law Review. 1995. "Recent Case." Harvard Law Review 108: 1208-13.

Johnson, Genevieve Fuji. 2009. "Deliberative Democratic Practices in Canada: An Analysis of Institutional Empowerment in Three Cases." Canadian Journal of Political Science 42 (3): 679-703.

Khanani, Intisar, et al. 2010. "The Impact of Prenatal WIC Participation on Infant Mortality and Racial Disparities." American Journal of Public Health 100 (1): S204-S209.

MacCoun, Robert. 2005. "Voice, Control, and Belonging: The DoubleEdged Sword of Procedural Fairness." Annual Review of Law and Social Science 1: 171-201. 
Menkel-Meadow, Carrie. 2004. "The Lawyer's Role(s) in Deliberative Democracy," Nevada Law Journal 5 (2): 347-69.

Merion, R.M., et al. 2005. "Deceased-Donor Characteristics and the Survival Benefit of Kidney Transplantation.” JAMA 294 (21): 2726-2733.

Minow, Martha. 1991. "From Class Actions to Miss Saigon: The Concept of Representation in the Law." Cleveland State Law Review 39 (3): 269300 .

National Commission for the Protection of Human Subjects of Biomedical and Behavioral Research. 1978. The Belmont Report: Ethical Principles and Guidelines for the Protection of Human Subjects of Research. Washington, DC.

Parkinson, John, and Declan Roche. 2004. "Restorative Justice: Deliberative Democracy in Action?" Australian Journal of Political Science 39 (3): 505-10.

Peikes, Deborah, et al. 2009. "Effects of Care Coordination on Hospitalization, Quality of Care, and Health Care Expenditures Among Medicare Beneficiaries: 15 Randomized Trials." JAMA 301 (6): 603-18.

Pitkin, Hanna Fenichel. 1967. The Concept of Representation. Berkeley: University of California Press.

Porter, Joan P. 1987. "How Unaffiliated/Nonscientist Members of Institutional Review Boards See Their Roles.” IRB 9 (6): 1-6.

President's Commission for the Study of Bioethical Issues. 2010. New Directions: The Ethics of Synthetic Biology and Emerging Technologies. Washington, DC.

---. 2012. Moral Science: Protecting Participants in Human Subjects Research. Washington, DC.

Recommendations for Community Involvement in National Institute of Allergy and Infectious Diseases HIV/AIDS Clinical Trials Research. 2009. Available at: http://www.hvtn.org/community/CAB_Recommendations_Certified.pdf.

Rosenbaum, Sara. 1992. "Mothers and Children Last: The Oregon Medicaid Experiment." American Journal of Law and Medicine 18 (1-2): 97-126. 
Rosenblatt, Rand. 1978. "Health Care Reform and Administrative Law: A Structural Approach." Yale Law Journal 88 (2): 243-336.

Sirotin, Nicole, et al. 2010. "IRBs and Ethically Challenging Protocols: Views of IRB Chairs about Useful Resources," IRB 32 (5): 10-19.

Veatch, Robert. "How Many Principles for Bioethics?” In Principles of Health Care Ethics, eds. Richard E. Ashcroft, Angus Dawson, and Heather Draper. London: Wiley, 2007.

Walters, Daniel. 2012. "The Justiciability of Fair Balance Under the Federal Advisory Committee Act: Toward a Deliberative Process Approach," Michigan Law Review 110: 677-708.

Beno v. Shalala, 30 F.3d 1057 (9th Cir. 1994).

C.K. v. New Jersey Department of Health \& Human Services, 92 F.3d 171 (3d Cir. 1996).

Crane v. Mathews, 417 F. Supp. 532 (N.D. Ga. 1976). 